\title{
X-RAY STRUCTURE OF (1,5,9,13-TETRAAZACYCLOHEXADECANE)ZINC(II) TETRABROMOZINCATE
}

\author{
Ki-Young Choi, ${ }^{1, *}$ Haiil Ryu, ${ }^{1}$ 11-Hwan Suh ${ }^{1,25}$ and Edward R.T. Tiekink*3 \\ 'Department of Cultural Heritage Conservation Science, Kongju National University, Kongju 314-701, Korea \\ kychoi@mail.kongju.ac.kr \\ ${ }^{2}$ Department of Physics, Chungnam National University, Taejon 305-764, Korea \\ ${ }^{3}$ Department of Chemistry, The University of Adelaide, Australia 5005, edward.tiekink@adelaide.edu.au
}

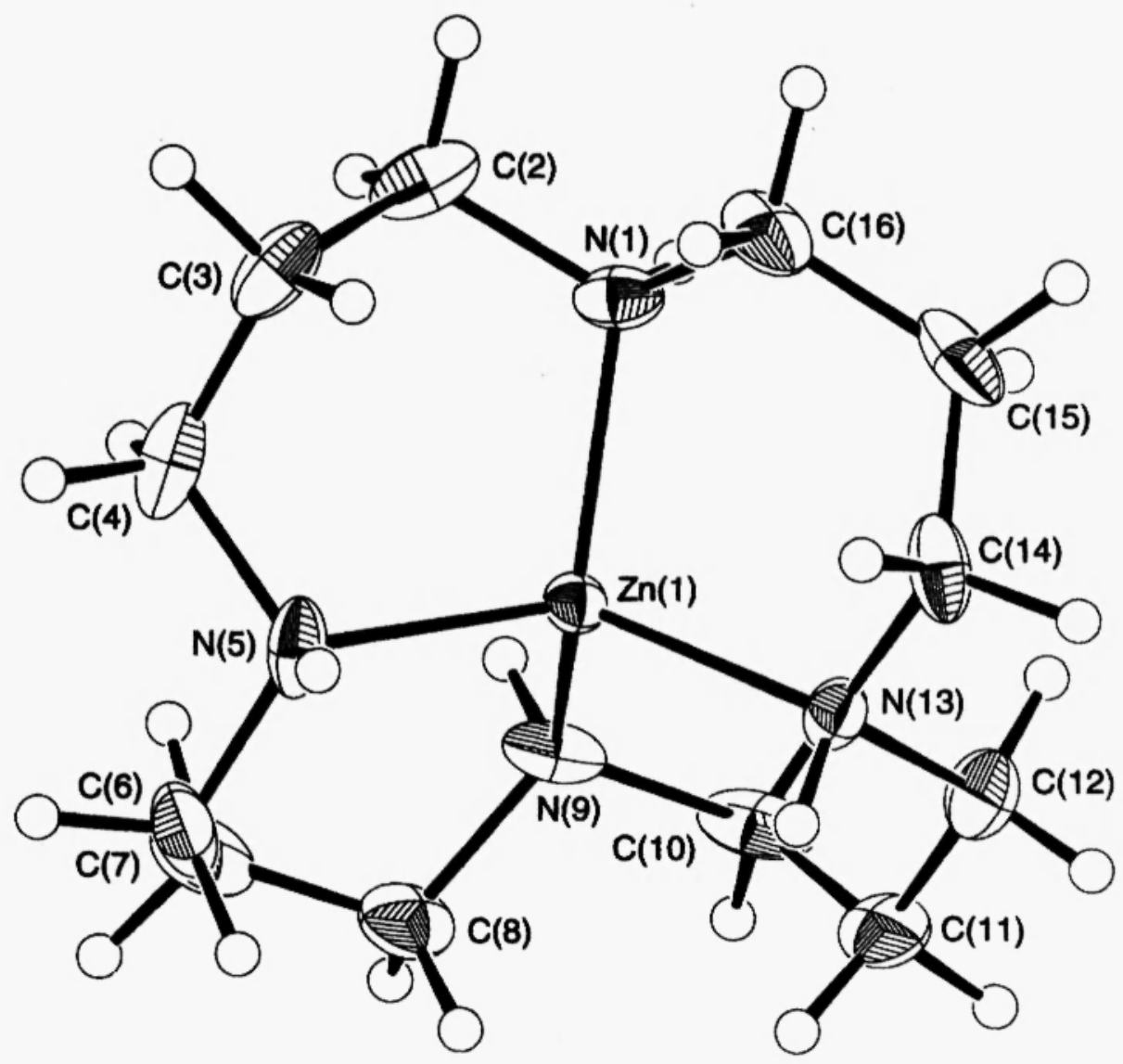

Figure 1. Molecular structure (50\% displacement ellipsoids) of the cation in the structure of $[\mathrm{ZnL}]\left[\mathrm{ZnBr}_{4}\right]$. Selected bond distances and angles: $\mathrm{Zn}(1)-\mathrm{N}(1)$ 2.023(5), $\mathrm{Zn}(1)-\mathrm{N}(5)$ 2.022(5), $\mathrm{Zn}(1)-\mathrm{N}(9)$ 2.017(5), and $\mathrm{Zn}(1)$ $\mathrm{N}(13)$ 2.013(5) A; N(1)-Zn(1)-N(5) 105.0(2), N(1)-Zn(1)-N(9) 120.5(2), N(1)-Zn(1)-N(13) 103.6(2), N(5)-Zn(1)$\mathrm{N}(9) 103.1(2), \mathrm{N}(5)-\mathrm{Zn}(1)-\mathrm{N}(13) 123.0(2)$, and $\mathrm{N}(9)-\mathrm{Zn}(1)-\mathrm{N}(13) 103.0(2)^{\circ}$.

\section{Comment}

The zinc atom in the cation exists in a distorted tetrahedral geometry defined by four nitrogen atoms derived from the macrocyclic ligand. The tetradentate mode of coordination results in the formation of four six-membered rings each of which adopts a chair conformation that is flattened somewhat at the zinc apex. The nitrogen-bound hydrogen atoms adopt a +-+- conformation [1] meaning that they sequentially lie to opposite sides of the macrocycle. The conformation reported here for the cation matches closely that found in the perchlorate analogue

${ }^{5}$ On sabbatical leave at the Department of Chemistry, The University of Adelaide, Australia 5005 
[1]. The widest angles subtended at the zinc atom, i.e. $\mathrm{N}(1)-\mathrm{Zn}(1)-\mathrm{N}(9)$ and $\mathrm{N}(5)-\mathrm{Zn}(1)-\mathrm{N}(13)$, may be related to the close association of the respective pairs of amine-hydrogen atoms with symmetry related $\left[\mathrm{ZnBr}_{4}\right]^{-}$anions. The closest such interaction of $2.49 \AA$ occurs between $\mathrm{N}-\mathrm{H}(9)$ and $\operatorname{Br}(1)^{2}$ so that $\mathrm{N}(9) \ldots \mathrm{Br}(1)$ is $3.403(6) \AA$ and the angle subtended at $H(9)$ is $167^{\circ}$ with symmetry operation $i: x, y,-1+z$.

\section{Experimental}

Preparation: The macrocyclic ligand, L, was prepared according to previously published procedure [2]. A methanol solution of $\mathrm{L}(114 \mathrm{mg}, 0.5 \mathrm{mmol})$ and $\mathrm{ZnBr}_{2}(225 \mathrm{mg}, 1 \mathrm{mmol})$ was heated at reflux for $1 \mathrm{~h}$. The solution was then taken to dryness and the resulting solid dissolved in acetonitrile/water $(1: 1,10 \mathrm{ml})$. When this mixture was allowed to stand for a few days, a quantity of colourless crystals were deposited. These were filtered off and dried in air. IR $\left(\mathrm{KBr}, \mathrm{cm}^{-1}\right): 3224 \mathrm{v}(\mathrm{N}-\mathrm{H})$. FAB mass (m/z): $678\left[\mathrm{ZnL}, \mathrm{ZnBr}_{4}\right]^{+}$.

Crystallography: An empirical absorption correction was applied [3]. The residual electron density peak (1.19 e $A^{-3}$ ) was located near the $\operatorname{Br}(4)$ atom.

Table 1. Crystallographic data for $[\mathrm{ZnL}]\left[\mathrm{ZnBr}_{4}\right]$

\begin{tabular}{|c|c|c|c|}
\hline Formula & $\mathrm{C}_{12} \mathrm{H}_{28} \mathrm{Br}_{4} \mathrm{~N}_{4} \mathrm{Zn}_{2}$ & Formula weight & 678.8 \\
\hline Crystal system & monoclinic & Space group & $P 2_{1} / n$ \\
\hline$a, A$ & $15.386(5)$ & $b, A$ & $15.668(4)$ \\
\hline$c, \AA$ & $9.036(4)$ & $\beta, 0$ & $103.76(5)$ \\
\hline $\mathrm{V}, \mathrm{A}^{3}$ & $2116(1)$ & $Z$ & 4 \\
\hline Crystal size, $\mathrm{mm}$ & $0.07 \times 0.26 \times 0.31$ & Diffractometer & Rigaku AFC7R \\
\hline Temperature, $\mathrm{K}$ & 173 & $\mu(\mathrm{Mo}-\mathrm{K} \alpha), \mathrm{cm}^{-1}$ & 98.45 \\
\hline$D_{\text {calod, }} \mathrm{g} \mathrm{cm}^{-3}$ & 2.131 & $F(000)$ & 1312 \\
\hline$A_{\max } 0$ & 27.5 & No. reflns meas., unique & 5220,4855 \\
\hline No. reflns with $I \geq 2 \sigma(I)$ & 2588 & $R, w R\left(F^{2}\right.$, obs. data $)$ & $0.032,0.066$ \\
\hline$R, w R\left(F^{2}\right.$, all data $)$ & $0.120,0.084$ & No. parameters & 200 \\
\hline Weighting scheme & \multicolumn{3}{|c|}{$w=1 /\left[\sigma^{2}\left(F_{0}{ }^{2}\right)+(0.0232 P)^{2}+1.9103 P\right]$ where $P=\left(F_{0}^{2}+2 F_{3}^{2}\right) / 3$} \\
\hline GoF & 0.99 & $\rho, e A^{-3}$ & 1.19 \\
\hline Programs used & \multirow{2}{*}{\multicolumn{3}{|c|}{$\begin{array}{l}\text { DIFABS [3], teXsan [4], DIRDIF [5], SHELXI } 97 \text { [6], ORTEP [7] } \\
\text { CCDC } 162618\end{array}$}} \\
\hline Deposition no. & & & \\
\hline
\end{tabular}

\section{Acknowledgements}

This work was supported by a Grant (No. 2001-1-12200-008-2) from the Basic Research Program of the Korea Science and Engineering Foundation. The Australian Academy of Science is gratefully acknowledged for support to allow I.-W.S. to spend sabbatical leave in Adelaide. The Australian Research Council is thanked for support of the crystallographic facility.

\section{References}

[1] R. Luckay, T.E. Chantson, J.H. Reibenspies and R.D. Hancock, J. Chem. Soc., Dalton Trans., (1995) 1363.

[2] W.L. Smith and K.N. Raymond, Inong. Synth., 20 (1980) 109.

[3] N. Walker and D. Stuart, Acta Crystallogr., A39 (1983) 158.

[4] teXsan, Single Crystal Structure Analysis Software, Version 1.04 (1997), Molecular Structure Corporation, The Woodlands, TX, U.S.A.

[5] P.T. Beurskens, G. Admiraal, G. Beurskens, W.P. Bosman, S. Garcia-Granda, R.O. Gould, J.M.M. Smits and C. Smykalla, The DIRDIF program system, Technical Report of the Crystallography Laboratory, University of Nijmegen, The Netherlands (1992).

[6] G.M. Sheldrick, SHELXL 97, University of Gottingen, Germany (1997).

[7] C.K. Johnson, ORTEPII, Report ORNL-5138, Oak Ridge National Laboratory, TN, U.S.A. (1976).

Received: April 20, 2001 - Accepted: April 27, 2001 - 